\title{
Indicators of Innovative Leadership for Secondary School Principals: Developing and Testing the Structural Relationship Model
}

\author{
Aimchit Somsueb ${ }^{1}$, Phrakru Sutheejariyawatana ${ }^{1} \&$ Paisan Suwannoi ${ }^{2}$ \\ ${ }^{1}$ Faculty of Education, Mahamakut Buddhist University Isan Campus, Khon Khaen, Thailand \\ ${ }^{2}$ Human Resource Development Center, Khon Khaen University, Khon Khaen, Thailand \\ Correspondence: Phrakru Sutheejariyawatana, Program of Educational Administration Program, Faculty of \\ Education, Mahamakut Buddhist University, Northeastern Campus, Thailand. Tel: 668-3149-3809. E-mail: \\ sakorn2514@gmail.com
}

Received: August 15, 2018

Accepted: September 21, $2018 \quad$ Online Published: January 30, 2019

doi:10.5539/ies.v12n2p11

URL: https://doi.org/10.5539/ies.v12n2p11

\begin{abstract}
The objectives of this research were to test the fitness of the model that developed from theory and research with empirical data and to verify the factor loading value of major components, sub-components, and indicators by using descriptive research methodology. Determine the sample size in proportion between sample unit and numbers of parameter 20:1 and selected 1,020 samples from 2,359 secondary school principals under the jurisdiction of the Office of the Basic Education Commission of Thailand by using proportional random sampling. Collecting data by using a set of rating scale questionnaires with reliability 0.97 . Data were analyzed by using AMOS Program. The research was based on the provided research hypotheses including Visionary Measurement Model (VIS), Collaborative Measurement Model (COL), Risk-taking Measurement Model (RISK), Oriented Change Measurement Model $(\mathrm{OCH})$ and Innovative Leadership Model were fit with empirical data. The main components, sub-components, and indicators were in accordance with the criteria.
\end{abstract}

Keywords: indicator, leadership, innovative leadership, innovative leadership for secondary school principals

\section{Introduction}

\subsection{Research Problem}

The Thai government has announced a policy of accelerating the development of the country by building a foundation for the future, based on the "Thailand 4.0" model, a need to transform the country's economic structure, driven by innovation. The strategy is to strengthen and develop human capital. To change people in Thai society values based on social norms and prepare people for life skills in the 21 st century, a digital society and innovation. Focus on creating creative people and have the ability to create or produce innovations, this policy challenges the reform of the Thai education system (The Secretariat of the Council of Education, 2014). One of the factors contributing to the quality of educational management at the Thai Teachers' Council is of continuous importance and has been set as one of the standards of the profession of educational administrators, i.e. leadership and leadership with the school administrators (Teachers Council, 2013). This is in line with the guidelines of the Office of Basic Education Commission (2014), which aims to promote basic education through the leadership of school administrators. It mentions leadership for education 4.0 that school administrators must be leaders in teaching and learning that will enable them to bring the knowledge that exists everywhere in the world to creative integration and innovation, various meet the needs of the society and consistent with the awareness of the reform of education, the government encourages training courses for school administrators including (a) digital school administration, (b) innovative leadership, (c) marketing strategy for schools, (d) school development strategy, (e) risk management for education, (f) management of change to quality culture, (g) develop relationships (Ministry of Education, 2016). Therefore, school administrators must have innovative leadership. It will result in the ability to work, innovation or something new useful for learners. This will allow the institution to develop a quality education on the basis of global change (Othman \& Rahman, 2013).

The innovative leadership is appropriate for school administrators in the present society. According to the synthesis of elements in which characterized the innovative leadership from 17 references including George (2012), Couros (2013), Owen (2015), Marron and Cunniff (2014), Sheffer (n.d.), Metcalf (2011), Othman and 
Rahman (2013), Sloane (2007), Mumford (2002, cited in Soliman 2014), Doss (2015), Metcalf and Moreli (2015), Maladzhi et al. (2012), Johannessen et al. (2014), Davidovich (2010), Rojanawattanaboon (2010) and Tonak et al. (2014), It was found that there were 35 main components of the theoretical framework. It was showed that there were varieties of the attitude toward the elements characterizing the innovative leadership. However, when considering the frequency of 6 and above, it is found that there were four elements which are used as the conceptual framework in the present study including visionary, collaboration, risk-taking, and oriented change, respectively.

We found that the development and testing of the model of structural relationships, the innovative leadership indicators for school administrators through the research process were very important. It would help to gain new knowledge of unity. The results of this study could be used as a guideline for the development of innovative leadership in school administrators. This is especially true for high school administrators under the jurisdiction of the Office of the Basic Education Commission. By setting goals and performance indicators for innovation or for monitoring and evaluation, it also supports the environment and work environment that facilitates the exchange of learning, creativity and innovation (Suwannawong, 2016). It is interesting to note that the structural relationship model of innovative leadership indicators developed based on the related theories and previous studies were consistent with the behavior or expression of secondary school administrators. Is the school under the jurisdiction of the Office of the Basic Education Commission? The school administrators themselves or their agencies could use the result from the present study as a guideline for development planning.

\subsection{Hypothesis}

The structural relationship model and the innovative leadership indicator for secondary school administrator were used in this study. We constructed and developed by using the method named the "Empirical Definition" where the structural relationship model was supported by theories and related previous studies (Wiratchai, 2002). We studied all related theories and previous studies in a systematic and logical ways from a variety of sources.

Hypothesis 1: The structural relationships of the innovative leaders for secondary school administrators developed by the researcher based on theoretical and previous studies were consistent with the empirical data according to the Hair's study (Hair et al., 2010) including (1) Relative Chi-square (CMIN/DF) was 1 -3 or less, (2) Root mean square error of approximation (RMSEA) was lower than 0.05, (3) Goodness-of-fit index (GFI), (4) Adjusted Goodness-of-Fit Index (AGFI), (5) Comparative Fit Index (CFI), and the Normalized Fit Index (NFI) was $0.90-1.00$, respectively.

Hypothesis 2: The model has structural integrity. The loading factor of the main component was $\geq 0.70$ (Farrell \& Rudd, 2009 cited in Tojib, 2009), and sub-components and indicator was $\geq 0.30$ (Tacq, 1997), respectively.

\subsection{Conceptual Framework}

Based on the results of the synthesis of the components characterized the innovative leadership features from the above 17 sources, it was found that there were four main components of the measurement of innovative leadership including (a) visionary, (b) cooperation collaboration, (c) risk-taking, and (d) change-oriented. The researcher further synthesized the sub-components of each key-component. To represent the measurement model of each key-components, it was found that (1) Visionary Model includes clear vision, vision communication, enthusiasm, building relationships, goal setting and values of mission, respectively, (2) Measurement Model of Collaborative includes empowered, openness, shared goal, involved in decision making, collaborative decision-making, and resource allocation, respectively, (3) Risk-taking Model includes decision-making, constant learning, confidence, acceptability, and calculated risks, respectively, and (4) Measurement Model of Oriented Change includes motivation, good communication skills, emotional intelligence, and commitment, respectively. These components were in the innovative leadership model measurement. The conceptual framework was shown in Figure 1. 


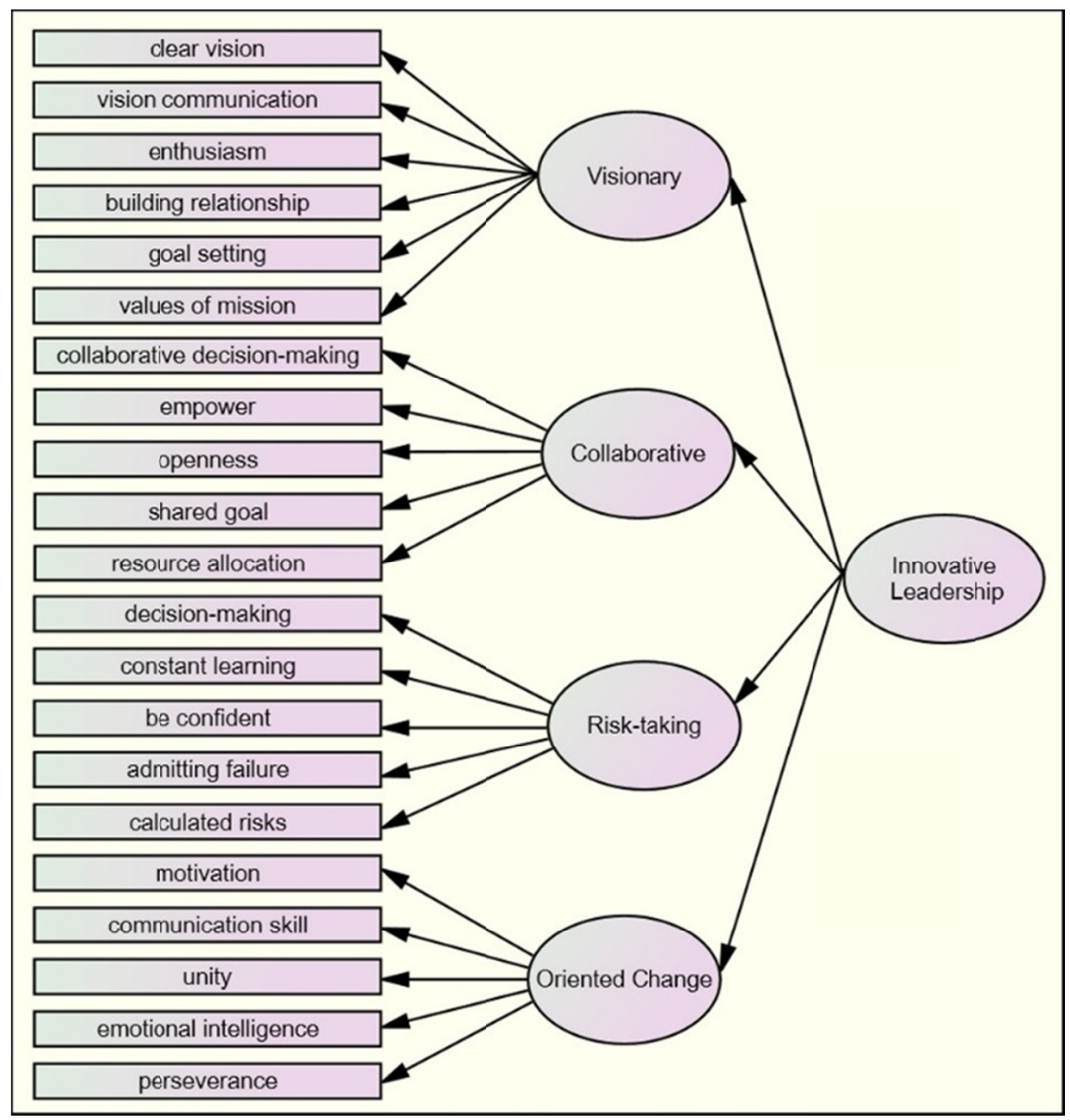

Figure 1. Hypothetical model: research framework

Based on the above hypothetical model, we studied the operational definitions of each sub-component which was linked to an indicator. An indicator reflected the leadership behavior of each sub-component. A total of 79 indicators were considered as a structural relationship model covering main components, sub-components, and indicators.

\subsection{Purpose of the Study}

The purpose of this study was to examine the consistency of the structural relationships model, indicator of the innovative leadership for the secondary school administrator, the Office of the Basic Education Commission (OBEC) which was developed by the researcher based on the related theories and empirical data. The consistency for each key and sub-key component as well as indicators was also compared with the criteria.

\section{Method}

\subsection{Participants}

The present study was a descriptive research which created and developed indicators using empirical definition. Population was the secondary school administrators under the Office of the Basic Education Commission, in academic year of 2016 (Office of Basic Education Policy and Planning, 2016). Sample size was determined by the ratio of the sample units to the number of parameters as 20:1 adopted from Gold (1980, cited in Wiratchai, 1999). The number of parameters was calculated from the combination of 5 variables, 21 parameters and 25 lines of influences. There were totally 51 parameters. The sample size was 1,020 .

\subsection{Materials}

The research instrument was divided into 2 parts: (1) Status of respondents, and (2) Behavioral questionnaire or the 
demonstration of innovative leadership of secondary school administrators in a rating scale. Contents were classified by main components and sub-components. There were 79 questions which were created and developed by research team. Procedures included (a) studying the related theories and previous studies for synthesis as a main component, (b) studying the related theories and previous studies to synthesize the sub-components, (c) studying the related theories and previous studies to summarize the operational definition linked to the determination, (d) creating a checklist for the language usage in each question and the consistency of the question with the indicator and definition, (e) providing to the experts in the field of educational administration, (f) examining the appropriateness of the idiomatic expressions and the consistency of the questions with the indicator and the operational definition, (g) updating the questionnaire and tried it out with non-sampled secondary school administrators. All data were also analyzed in order to find the alpha coefficient of reliability using the Cronbach method (National Institute of Development Administration (NIDA), 2003). The reliability of the questionnaire was 0.97 . The visionary component was 0.94 . The risk factor was 0.93 . The change-oriented component was 0.9 , respectively.

\subsection{Data Collection}

This study was conducted between August and December 2017 using a proportional random sampling method. The proportional random sampling was used to obtain the sample of 1,020 out of 2,359 populations and then sent the questionnaire to the random sample by normal mail accompanied by the letter from the Faculty of Graduate Studies, Mahamakut Buddhist University Northeastern Campus, Thailand. Only 882 questionnaires were returned, representing $86.47 \%$ of the total questionnaires. When considering the value Kaiser-Mayer-Olki (KMO) test of Sampling Adequacy for each measurement model of the four main components. Values between .918-.939 revealed that the number of samples used in this study was sufficient for the confirmatory factor analysis.

\subsection{Data Analysis}

We analyzed all data by using statistical program for the following statistical perspectives: (1) frequency and percentage of the sample, (2) mean and distribution coefficient, (3) Pearson's correlation coefficients (West, Taylor, \& Wu, 2012) and Bartlett's statistics (Tobias \& Carlson, 2010) values were used to determine the appropriateness of the indicator. To determine the suitability of the variables, the Kaiser-Meyer-Olkin (KMO) Test was done, for sampling adequate (Cerny \& Kaiser, 1977), and (4) component analysis. First order confirmatory factor Analysis was used to create the scale element whereas the second order confirmatory factor Analysis was used to develop the indicator using statistical packages and AMOS programs (Bartholomew et al., 2011). The results of the weighing of the composition showed that the main components, sub-components, and all the indicators had positive values as follows: (a) four main components of innovative leadership (INNO) ranged from 0.89 to 1.00 , and (b) six components of the main components were vision (VIS) where the coefficients ranged from 0.83 to 1.00 , (c) there were 5 components of the main component where the Collaboration (COL) ranged from 0.90 to 1.03 , (d) five components of RISK ranged from 0.94 to 1.03 . The five major components of change (OCH) were $0.98-1.07$. In addition, it was found that the factor loading of the 79 indicators was positive, ranging from 0.81 to 1.16 and statistically significant at .01 . The Structural Relationship Model Innovative Leadership Indicators for secondary school administrators consisted of four main components, 21 sub-components and 79 indicators which were used as a framework for developing innovative leadership for secondary school administrators.

\section{Results}

Prior to data analysis to test the consistency of the model, the structural relationships of the indicator of innovative leadership of secondary school administrators developed according to the related theories and previous studies with empirical data. The data were analyzed to determine the appropriateness of the indicator for selection in the model. Based on Kan's study (2004), the mean was equal to or higher than 3.00 and has a distribution coefficient equal to or less than $20 \%$ It was found that 79 indicators had average values between 4.26-4.76 and distribution coefficients between 9.27-14.41, indicating that the indicators were appropriate. It could be selected in all structural relationships. After that all data were analyzed in order to test the consistency. The result of the model-based consistency test developed from related theories and previous studies with empirical data from the first affirmative factor analysis. It was found that (1) vision model CMIN/DF $=2.335$, RMSEA $=0.039$, GFI $=$ $0.951, \mathrm{AGFI}=0.932, \mathrm{CFI}=0.979$, and NFI $=0.963(2)$ cooperation model $\mathrm{CMIN} / \mathrm{DF}=2.238, \mathrm{RMSEA}=0.037$, $\mathrm{GFI}=0.977, \mathrm{AGFI}=0.960, \mathrm{CFI}=0.991$ and $\mathrm{NFI}=0.983(3)$ risk model $\mathrm{CMIN} / \mathrm{DF}=2.954, \mathrm{RMSEA}=0.047, \mathrm{GFI}$ $=0.958, \mathrm{AGFI}=0.936, \mathrm{CFI}=0.981$, and NFI $=0.971(4)$ changes model CMIN $/ \mathrm{DF}=2.551, \mathrm{RMSEA}=0.042$, $\mathrm{GFI}=0.964, \mathrm{AGFI}=0.944, \mathrm{CFI}=0.986$ and NFI $=0.977$. The secondary confirmation analysis showed that innovative model was consistent with the innovative leadership model as CMIN/DF $=2.353$, RMSEA $=0.039$, $\mathrm{GFI}=0.963, \mathrm{AGFI}=0.944, \mathrm{CFI}=0.986$ and $\mathrm{NFI}=0.977($ Table 1$)$. 
Table 1. First and second affirmative analysis results to test the consistency of models developed from theory and research with empirical data

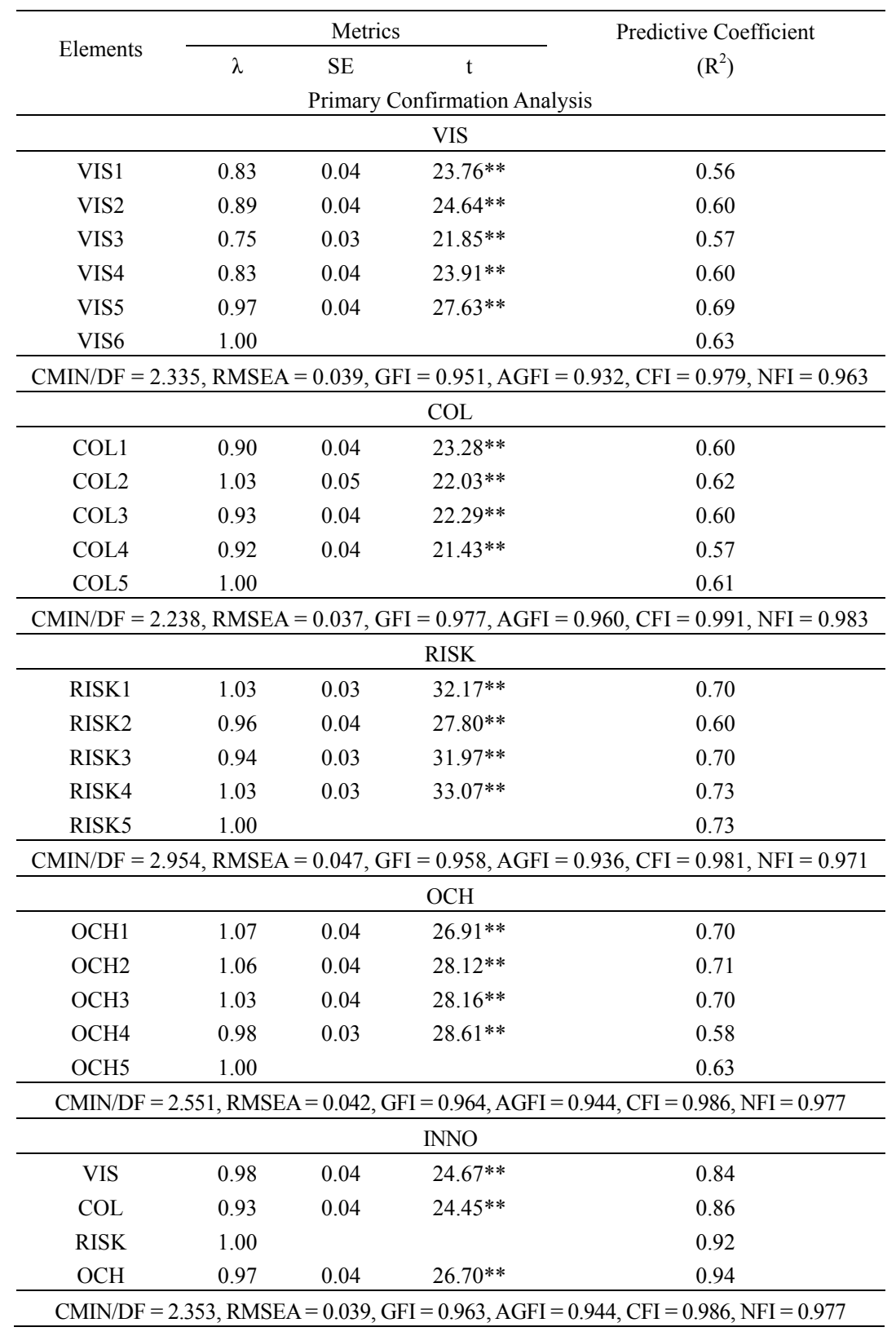

\section{Discussion}

Based on the findings, the models developed from the related theories and previous studies were consistent with the empirical data. The models analyzed the most affirmative components including Vision Measurement Model (VIS), Collaborative Measurement Model (COL), Risk Measurement Model (RISK), and Measurement Model of Change $(\mathrm{OCH})$, respectively. The second-highest affirmation model was the INNO model. These could be explained into two cases as follows:

(a) In the case of Outside-In look, it was based on the related theories and previous studies that were synthesized to form the structural relationships of the indicators of innovative leadership of secondary school administrators. Although the related theories and previous studies were from foreign countries, they were consistent with the expression or behavior of high school administrators in the present study. This is due to the universality of the related theories and previous studies outcomes as it has separated throughout the world as globalization as "We are moving towards a new era of globalization called digital globalization. It is the age of information and information flow such as the concept of research, technology, talent, and even the outstanding activities that can be accessed 
around the world", according to Reiche (2016). However, Lund and Manyika (2017) argued that it is because the Internet is a necessity for today's people to find information, consumption or even business. The flow of this change has occurred quickly. It might be based on the concept of innovation diffusion. In the view of Roger (1995), who invented and proved the theory of diffusion of innovation (Diffusion of Innovation Theory), the belief that social and cultural change raised from the diffusion of new things, from one society to another, society and society take on new things. This is called the innovation which is knowledge, ideas, techniques, methods, and new technologies. Kammerzelt's (2017) observation also stated that "Innovations and new technologies are changing the world and the everyday lives of each and every one of us." Innovation and technology are changing the world and our everyday lives, from a globalized perspective. In view of the advances in digital technology or the internet and the views of innovation diffusion, the related theories and previous studies that have been developed in the present study were consistent with the expression and the empirical behavior of the research sample.

(b) In the case of an Inside-Out look, it was based on the empirical data of the sample used in the present study which was developed or influenced by various factors. In the Thai society or Thai educational system, the innovative leadership demonstrated in the same direction as shown in the related theories and previous studies in the present study. In the present, there were seven training courses for the administrators of educational institutes including (1) innovative leadership, (2) marketing strategies for schools, (3) educational development strategy, (4) risk management for schools' management of change to quality culture, and (5) relationship development strategies (Ministry of Education, 2013). According to the National Economic and Social Development Plan No. 12, 2017 - 2021, the development of innovation and innovation is the driving force behind all aspects of Thailand's development (National Economic and Social Development Board, 2016) or the National Education Plan (BE 2560-2579), which aims to develop teachers and educational personnel to be developed in accordance with the standards. There is a developmental approach, which is designed to system and model development teachers. Also, the educational personnel enhanced the country's development according to the 20 -year national strategy and the Thailand 4.0 strategy by teachers at all levels. All types of education have been developed in accordance with professional standards (Office of the Basic Education Commission, 2017). The development in such a way was consistent with the main components, sub-elements and the indicators used in this study. As a result, the leadership of the secondary school administrators in this research was characterized by innovative leadership that was consistent with the related theories and previous studies used in this study.

Beside using as theoretical models to develop innovative leadership for secondary school administrators, it could be used for both academically and practically in other cases including (a) applying the structural model of the innovative leadership indicator from this research to examine the consistency with empirical data of other target subjects such as primary and secondary school administrators, (b) conducting further study with other research methodology such as structural equation modeling, research and development, or participatory action research, respectively, (c) encouraging qualitative research to determine the key components, sub-components and an indicator of innovative leadership for secondary school administrators in order to get the model from real phenomena in Thai society. It can be used to compare to other models developed based on theories and previous studies, and (d) using as a guideline for planning or establishing criteria in assessing innovative leadership for personnel development in accordance with the strengths and weaknesses, respectively.

\section{Conclusion}

The study was based on the hypotheses related to the visionary measurement model (VIS), the collaborative measurement model (COL), the risk-taking measurement model (RISK), the oriented change measurement model $(\mathrm{OCH})$ and the innovative leadership model. The results were corresponded to the empirical data. All key components, minor components, and indicators were in accordance with the criteria.

\section{References}

Bartholomew, D., Knotts, M., \& Moustaki, I. (2011). Latent variable models and factor analysis: A unified approach (3rd ed.). West Sussex, UK: John Wiley \& Sons. https://doi.org/10.1002/9781119970583

Cerny, C. A., \& Kaiser, H. F. (1977). A study of a measure of sampling adequacy for factor-analytic correlation matrices. Multivariate Behavioral Research, 12(1), 43-47. https://doi.org/10.1207/s15327906mbr1201_3

Couros, G. (2013). Five characteristics of change agent. Retrieved September 23, 2016, from http://georgecouros.ca/blog/archives/3615

Davidovich, R. (2010). Beyond school improvement: The journey to innovative leadership. United States: Corwin Press. https://doi.org/10.4135/9781483350387

Doss, H. (2015). Five-character traits of innovation leaders. Retrieved December 26, 2015, from 
https://bit.ly/1NwKuEL

Farrell, A. M., \& Rudd, J. M. (2009). Factor analysis and Discriminant validity: A brief review of some practicalissues. In D. Tojib (Ed.), ANZMAC 2009 conference proceedings ANZMAC.

George, B. (2012). Five traits of innovative leadership. Retrieved January 8, 2016, from https://bit.ly/2GtyUQ7

Gold, R. Z. (1980). Introduction to bivariate and multivariable analysis. Illinois: Scott, Forman.

Hair, J. F., Black, W. C., Babin, B. J., \& Anderson, R. E. (2010). Multivariate data analysis (7th ed.). Upper Saddle River, NJ: Prentice Hall.

Johannessen, J., \& Skaalsvik, H. (2014). Innovative leadership in organizations: The road to innovation performance. Problems and Perspectives in Management, 12(2), 139-152.

Kammerzelt, A. (2017). What is technology? And why is it so important for us in everyday life? Retrieved February 3, 2018, from https://bit.ly/2pZYsda

Lund, S., \& Manyika, J. (2017). Defending digital globalization. Retrieved February 3, 2018, from https://fam.ag/2EgaROm

Maladzhi, W. R., Yan, B., \& Makinde, D. (2012). The impact of innovative leadership on organizational culture within South African small and medium enterprises in Western Cape, South Africa. African Journal of Business Management, 6(39), 10438-10444. https://doi.org/10.5897/AJBM12.749

Marron, J. M., \& Cunniff, D. (2014). What is an innovative educational leader? Contemporary issue in education research-second quarter, 7(2), 146-148.

Metcalf, M. (2011). Innovative leadership. Retrieved November 28, 2016, from https://bit.ly/2MTfZxw

Metcalf, M., \& Moreli, C. (2015). The art of learning change: Innovative leaders' transformational model. Retrieved May 20, 2016, from https://bit.ly/2H4GJIO

Ministry of Education. (2016). Educational reformation. Retrieved February 12, 2018, from https://bit.ly/2LDEsWK

National Economic and Social Development Board. (2017). National Economic and Social Development Plan No. 12 (2017-2021). Retrieved February 10, 2018, from http://www.nesdb.go.th/ewt_dl_link.php?nid=6422

Office of Basic Education Commission. (2014). A guide to performance evaluation of school administrators. Bangkok: Tongkamon Ltd.

Office of Basic Education Commission. (2017). The importance of the official plan for the fiscal year 2018 of the Office of the Basic Education Commission (For the submission of the annual budget request for 2018). Retrieved February 10, 2018, from http://www.obec.go.th/node/81701

Office of Basic Education Policy and Plan. (2017). The list of schools under the OBEC. Retrieved March 2, 2017, from https://bit.ly/2GtDT2X

Othman, A., \& Rahman, H. A. (2013). Innovative Leadership: Learning from Change Management among Malaysian Secondary School Principals. World Applied Sciences Journal, 23(2), 167-177.

Owen, S. (2015). Innovative leadership for 21st century skill-building: The principal's role in establishing futures-oriented teacher and student learning cultures and practices. Paper presented to learner conference, Madrid, Spain.

Reiche, S. (2016). Digital globalization: The new era and its implications. Retrieved February 3, 2018, from https://bit.ly/2GMfHIv

Roger, E. M. (1995). Diffusion of Innovations (4th ed.). Retrieved on January 15, 2018, from https://bit.ly/2t3HoXJ

Rojanawattanaboon, O. (2010). Model of factors influencing innovative leaders. Doctor of Public Administration. National Institute of Development Administration.

Sarnratana, V. (2013). New Paradigms in 21st Century Education. Bangkok: Tipwisut.

Sarnratana, V. (2015). Educational Administration Research: Concept, guideline, and Case Study (4th ed.). Bangkok: Tipwisut.

Sheffer, G. (n.d.). Innovative Leaders in international politics. Retrieved December 26,2015, from https://bit.ly/2GssksY 
Sloane, P. (2007). The innovative leader. United States: Kogan Page Limited.

Suwannawong, A. (2016). Innovative leaders. Retrieved February 18, 2017, from https://bit.ly/2q015uI

Tacq, J. (1997). Multivariate analysis techniques in social science research: From problem to analysis. London: SAGE Publications Ltd.

Takong, S. (2560). Indicators of moral leadership for administrators in basic education schools: A structural relationship model (The doctor degree of doctor of education, Faculty of education Mahamakut Buddhist University).

Teacher Council. (2014). Professional Standard for school administrators. Retrieved January 10, 2018, from https://bit.ly/2aHX9uO

The Secretariat of the Council of Education. (2014). Research Report on the Development of Thai Education and the Preparation for the 21st Century. Bangkok: Prikwaan Graphic.

Tobias, S., \& Carlson, J. E. (2010). Brief report: Bartlett's test of sphericity and chance findings in factor analysis. Journal of Multivariate Behavioral Research, 4(3). https://doi.org/10.1207/s15327906mbr0403_8

Tonak, K. et al. (2014). A Factor analysis of innovation leadership for basic educational administrators. Educational Journal of Naresuan University, 16(4), 131-139.

West, S. G., Taylor, A. B., \& Wu, W. (2012). Model fit and model selection in structural equation modeling. In R. H. Hoyle (Ed.), Handbook of structural equation modeling. New York: Guilford.

Wiratchai, N. (1999). Lisrel model: Analytical Statistics for Research (3rd ed.). Bangkok: Chulalongkorn University.

Wiratchai, N. (2002). Development of indicators for administration and management assessment of Educational Service Area. Bangkok: Tarn-uksorn.

\section{Copyrights}

Copyright for this article is retained by the author(s), with first publication rights granted to the journal.

This is an open-access article distributed under the terms and conditions of the Creative Commons Attribution license (http://creativecommons.org/licenses/by/4.0/). 